\title{
High Frequency of Obesity in Acne Keloidalis Nuchae Patients: A Hypothesis from a Brazilian Study
}

\author{
Andrea Mizuno Matsunaga ${ }^{a}$ Violeta Duarte Tortelly ${ }^{b}$ Carla Jorge Machado ${ }^{c}$ \\ Ludmila Ribeiro Pedrosa $^{d}$ Daniel Fernandes Melo ${ }^{b}$
}

${ }^{a}$ Dermatology Department, Federal Hospital of State Servants (HFSE), Rio de Janeiro, Brazil; ${ }^{b}$ Dermatology Department, University of State of Rio de Janeiro (UERJ), Rio de Janeiro, Brazil; 'Preventive and Social Medicine Department, Federal University of Minas Gerais, Belo Horizonte, Brazil; 'Dermatology Department, Marcílio Dias Naval Hospital, Rio de Janeiro, Brazil

\section{Established Facts}

- Acne keloidalis nuchae $(\mathrm{AKN})$ is a chronic inflammatory condition that almost exclusively affects the occipital and nape areas, being much more common in men, especially in African descendants from puberty to 50 years of age.

- AKN has long been associated with friction and local trauma due to shirt collars, hats, helmets, and close shaves as triggering factors. Furthermore, keratinization disorders of genetic origin, folliculitis decalvans, seborrhea, increased androgen levels, the use of some medications, and metabolic syndrome have also been cited as possible causes.

\section{Novel Insights}

- Overweight and obesity per se might be related to the development of acne keloidalis nuchae (AKN). Even though insulin resistance and metabolic syndrome are frequently present in patients with high $\mathrm{BMI}$, this is not always true. A high frequency of obesity in patients with AKN suggests these 2 conditions may be concurrent.

- Redundant skin folds in the nape of patients with obesity might act as a trigger for the development of $\mathrm{AKN}$ in predisposed patients. Adipose tissue accumulation in the nape, the only moving part of the scalp, would deepen local skin creases, leading to constant trauma and an inflammatory process that could be part of the etiopathogenesis of AKN.

\section{Keywords}

Acne keloidalis nuchae - Obesity · Hair disorders ·

Scarring alopecia

\section{Abstract}

Acne keloidalis nuchae (AKN) is a chronic inflammatory condition that almost exclusively affects the occipital and nape areas. Although not completely understood, its etiopathogenesis seems to be multifactorial, including association with metabolic syndrome (MetS). Despite being commonly seen in patients with MetS, obesity per se as a possible related factor for AKN has yet to be studied. The aim of this study was to evaluate the relationship between obesity and $\mathrm{AKN}$ in a series of patients. Eight male patients, with a median age of 38 years (range 1548), were included. Overweight/obesity was found in $8 / 8$ (100\%), with median BMI of 32.2 (range $27.7-43.85 \mathrm{~kg} / \mathrm{m}^{2}$ ), including 2 patients with class 3 obesity. We hypothesize adipose

$\begin{aligned} & \text { karger@karger.com } \\ & \text { www.karger.com/sad }\end{aligned}$
Karger $\%$

Andrea Mizuno Matsunaga

Dermatology Department, Federal Hospital of State Servants (HFSE) R. Sacadura Cabral

178, Saúde, Rio de Janeiro 20221-903 (Brazil)

andreamizuno@gmail.com 
tissue accumulation in the nape, the only moving part of the scalp, leads to redundant skin folds, more friction, and inflammation, triggering AKN. This paper highlights the possible relationship between AKN and overweight/obesity, hypothesizing a mechanism for their contribution to the etiopathogenesis of this scalp disorder. To the best of our knowledge, this is the first study focused specifically in this association. While general physicians should pay attention to the appearing of AKN in overweight/obese patients, dermatologists must be aware that AKN patients should be assessed beyond the skin.

(C) 2020 S. Karger AG, Basel

\section{Introduction}

Acne keloidalis nuchae (AKN), or folliculitis keloidalis, is a chronic inflammatory condition that almost exclusively affects the occipital and nape areas [1]. Clinically, early AKN presents with papules and pustules that tend to coalesce, leading to disfiguring scarring alopecia. Trichoscopy shows, in early stages, erythematous follicular papules and pustules, perifollicular scales, and hemorrhagic and honey-colored crusts. As the disease progresses, perifollicular white halos (representing fibrosis), black dots, broken hair shafts, and dilated follicular ostia with keratin or hair tufts (polytrichia) can also be seen. In keloid-like lesions, milky-red areas with no follicular ostia prevail [2]. Symptoms such as itching, pain, and bleeding may be present [1]. AKN has an estimated prevalence in different populations ranging from $0.007 \%$ in an Asian series to $13.6 \%$ in African American football players [3, 4]. Men are more affected than women (7:1-35:1), and $\mathrm{AKN}$ has been mainly described in young adults, after puberty, being rare to start after 50 years of age [5-7].

Although not completely understood, the etiopathogenesis of AKN is believed to be multifactorial. A few papers have suggested that insulin resistance (IR) and metabolic syndrome (MetS) might be included among these factors $[6,8-11]$. Obesity, in spite of being commonly seen in patients with IR and MetS, as a risk factor for AKN has yet to be studied. The aim of this study was to evaluate the possible relationship between obesity and AKN in a series of patients.

\section{Case Report}

Patients with confirmed clinical and trichoscopic diagnosis of AKN were invited to participate. Clinical and trichoscopic images (Dermlite DL4 ${ }^{\circledR}$, 3 Gen Inc., San Juan Capistrano, CA, USA) of the affected areas were prospectively obtained from those who agreed to be included (shown in Figs. 1, 2). Clinical and epidemiological data were collected during interview, followed by laboratory blood tests.

A BMI of 25 to $<30 \mathrm{~kg} / \mathrm{m}^{2}$ was defined as overweight; 30 to $<35$ $\mathrm{kg} / \mathrm{m}^{2}$, class 1 obesity; 35 to $<40 \mathrm{~kg} / \mathrm{m}^{2}$, class 2 obesity; and 40 $\mathrm{kg} / \mathrm{m}^{2}$ or higher, class 3 obesity. MetS was diagnosed according to the American Heart Association (AHA) criteria, when 3 or more of the following were present: systolic blood pressure $\geq 130 \mathrm{~mm} \mathrm{Hg}$ or diastolic blood pressure $\geq 85 \mathrm{~mm} \mathrm{Hg}$; waist circumference $\geq 102$ $\mathrm{cm}$ in men or $\geq 88$ in women; fasting glucose $\geq 100 \mathrm{mg} / \mathrm{dL}$; triglycerides $\geq 150 \mathrm{mg} / \mathrm{dL}$; and HDL-c $<40 \mathrm{mg} / \mathrm{dL}$. The main features analyzed are summarized in Table 1.

A total of 8 patients, all male, with a median age of 38 years (range 15-48) were included; 6/8 (75\%) had Fitzpatrick skin phototype IV-VI. Duration of illness at first assessment was 1 year or longer in $5 / 8(62.5 \%)$, with a median duration of 4 years (range $0.5-20)$. Overweight and obesity were found in $8 / 8(100 \%)$ with median BMI of $32.2\left(\right.$ range $\left.27.7-43.85 \mathrm{~kg} / \mathrm{m}^{2}\right)$, including 2 patients with class 3 obesity. Systolic blood pressure $\geq 135 \mathrm{~mm} \mathrm{Hg}$ or diastolic blood pressure $\geq 85 \mathrm{~mm} \mathrm{Hg}$ was observed in $7 / 8$ (87.5\%) and waist circumference $\geq 102 \mathrm{~cm}$ in $4 / 8(50 \%)$. Fasting glucose higher than $99 \mathrm{mg} / \mathrm{dL}$ was found in $5 / 8(62.5 \%)$. Elevated triglycerides were present in $1 / 8(12.5 \%)$ and reduced HDL-C was observed in 2/8 (25\%). Overall, $5 / 8$ (62.5\%) met the AHA criteria for the diagnosis of MetS.

\section{Discussion/Conclusion}

The etiopathogenesis of AKN seems to be multifactorial. Curly ingrown hairs, as described in beard pseudofolliculitis, would be a possible mechanism, which, however, has not been histologically proven [12]. Friction and local trauma due to shirt collars, hats, helmets, and close shaves are commonly cited as triggering factors. Keratinization disorders of genetic origin [13], folliculitis decalvans [1], seborrhea, increased androgen levels or peripheral sensitivity to them $[1,6,8]$, and use of cyclosporine [14], tacrolimus [15], diphenylhydantoin, and carbamazepine [16] have also been correlated. In addition, some authors postulate that $\mathrm{AKN}$ causes a primary scarring alopecia, in which different antigens present in the follicles could trigger an inflammatory process. This would lead to weakening of the follicular barrier and hair shaft exposure, worsening the inflammation, and culminating in hypertrophic scars [12].

$\mathrm{AKN}$ frequently is a stigmatizing disease, causing an important impact on those affected, especially on the psychosocial aspect. Nevertheless, it may have other implications. All our patients were overweight or obese and part of them also had MetS. Even though these conditions are frequently associated, this is not always true. A previous study found, among others, a statistically significant association between $\mathrm{AKN}$ and high BMI, indicating that, in the case group, $25.7 \%$ were obese. When overweight was 


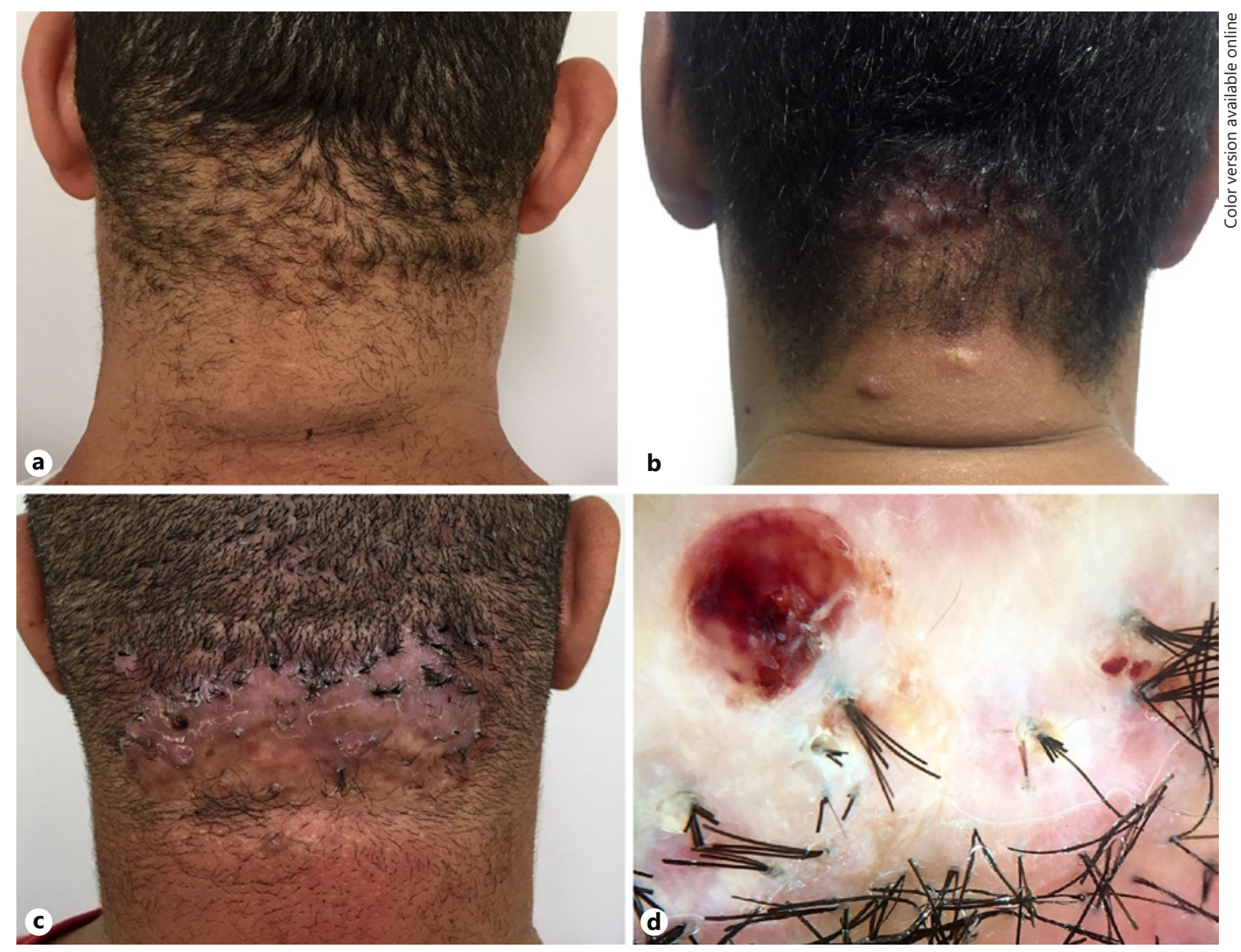

Fig. 1. AKN clinical presentation. Initial alopecia with follicular erythematous papules (a); erythematous papules coalescing into a plaque of alopecia (b); plaque of scarring alopecia, hair tufts or polytrichia, and perifollicular scales (c); and $\times 40$ magnification trichoscopy showing milky-red areas indicative of fibrosis, polytrichia, and hemorrhagic crusts $(\mathbf{d})$.

considered along with obesity, figures reached $62.3 \%$ [17]. Our study found these frequencies to be 62.5 and $100.0 \%$, respectively, corroborating that overweight and obesity may be related to the presence of AKN.

IR and MetS are especially related to central obesity and visceral fat (large waist circumference), which were present in only half of our patients, as opposed to general obesity and overweight (high BMI) in all of them. Therefore, we hypothesize that adipose tissue accumulation in the nape, the only moving part of the scalp, occurs in patients with overweight and obesity, leading to the formation of redundant skin folds. These deeper skin creases would cause more frequent local friction and consequent inflammation, acting as a trigger to the development of $\mathrm{AKN}$ in predisposed patients. The increased incidence of AKN in American football players reinforces our proposition, as it appears to be due not only to the helmet but also to their particular anthropometric measurements [4].
Furthermore, it is known that obesity has multiple effects on skin physiology, including disturbances in its barrier function, sebum production, sweat glands, lymphatic vessels, collagen structure and function, wound healing, micro- and macrocirculations, and subcutaneous tissue [18]. Several skin conditions such as hidradenitis suppurativa and psoriasis have already been described to be worsened by increased body fat $[19,20]$. AKN seems to be one more of them. Limitations of this study include a small sample size and the absence of histopathological examination of the affected area, despite the fact that the diagnosis of $\mathrm{AKN}$ is eminently clinical and reinforced by trichoscopy.

In conclusion, this paper hypothesizes a possible relationship between AKN and overweight or obesity, proposing a mechanism for their contribution to the etiopathogenesis of this often-neglected scalp disorder. To the best of our knowledge, this is the first study focused specifically in this association. Further studies with a larg- 


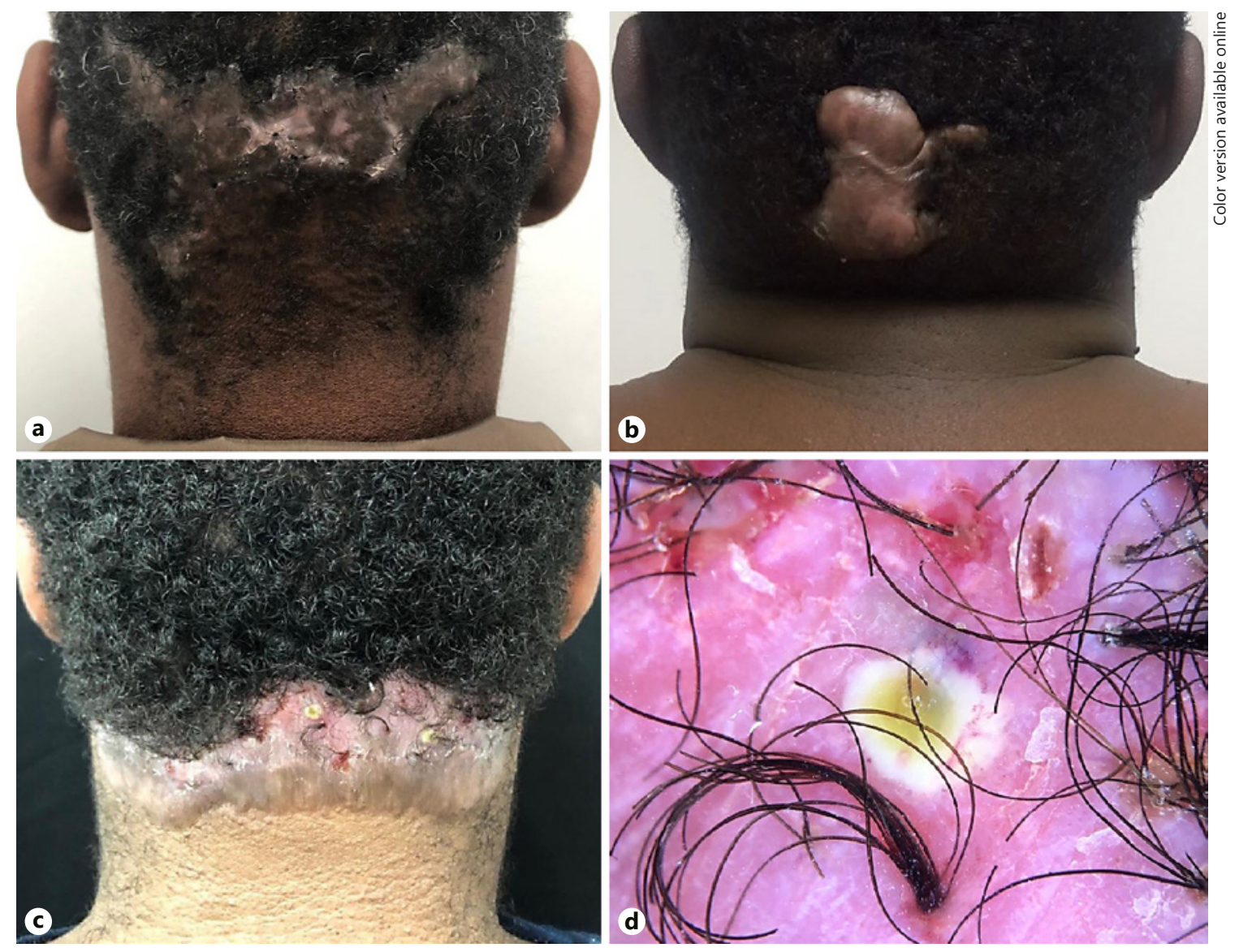

Fig. 2. Clinical aspects of AKN. Normochromic and erythematous papules on the occipital scalp and nape, large plaque of scarring alopecia with hypochromic areas indicating fibrosis (a); keloid-like mass on the occipital scalp (b); late stage with surgical scar, normochromic papules on the nape, plaque of scarring alopecia with scales, pustules, and hemorrhagic crusts, showing ongoing disease activity (c); and $\times 40$ magnification trichoscopy with erythema, perifollicular pustule, scales, hair tufts, and hemorrhagic crusts (d).

Table 1. Demographic and clinical description of $8(n=8)$ male study patients

\begin{tabular}{|c|c|c|c|c|c|c|c|c|c|c|}
\hline $\begin{array}{l}\text { Patient } \\
\text { ID }\end{array}$ & $\begin{array}{l}\text { Age, } \\
\text { years }\end{array}$ & $\begin{array}{l}\text { Skin } \\
\text { phototype }\end{array}$ & $\begin{array}{l}\text { Disease } \\
\text { duration, years }\end{array}$ & BMI & $\begin{array}{l}\text { Blood } \\
\text { pressure* }\end{array}$ & $\begin{array}{l}\text { Waist } \\
\text { circumference* }\end{array}$ & $\begin{array}{l}\text { Fasting } \\
\text { glucose* }\end{array}$ & Triglycerides* & HDL-c* & MetS \\
\hline 1 & 44 & IV & 20 & 36 & $150 \times 100$ & 124 & 109 & 137 & 33 & Yes \\
\hline 2 & 41 & VI & 7 & 43.85 & $140 \times 90$ & 133 & 112 & 98 & 41 & Yes \\
\hline 3 & 24 & $\mathrm{~V}$ & 10 & 32.93 & $140 \times 80$ & 99 & 107 & 110 & 37 & Yes \\
\hline 4 & 40 & III & 1 & 27.7 & $130 \times 85$ & 97 & 95 & 154 & 44 & No \\
\hline 5 & 48 & VI & 0.5 & 28.54 & $130 \times 90$ & 96 & 109 & 135 & 58 & No \\
\hline 6 & 15 & IV & 0.5 & 41.52 & $150 \times 90$ & 126 & 118 & 78 & 62 & Yes \\
\hline 7 & 37 & III & 8 & 29.4 & $110 \times 70$ & 96 & 94 & 132 & 74 & No \\
\hline 8 & 28 & VI & 0.5 & 31.51 & $150 \times 100$ & 121 & 107 & 42 & 64 & Yes \\
\hline
\end{tabular}

* American Heart Association (AHA) diagnostic criteria for metabolic syndrome (MetS) (3 or more present): systolic blood pressure $\geq 130 \mathrm{~mm} \mathrm{Hg}$ or diastolic blood pressure $\geq 85 \mathrm{~mm} \mathrm{Hg}$, waist circumference $\geq 102 \mathrm{~cm}$ (men), fasting glucose $\geq 100 \mathrm{mg} / \mathrm{dL}$, triglycerides $\geq 150 \mathrm{mg} / \mathrm{dL}$, and HDL-c $<40 \mathrm{mg} / \mathrm{dL}$. BMI normal reference range: $18.5-25 \mathrm{~kg} / \mathrm{m}^{2}$. 
er number of patients are needed to corroborate these results. We believe that IR and MetS may influence the development of $\mathrm{AKN}$ in patients with overweight and obesity. However, redundant skin folds in the neck may also play a role in this process. Therefore, if our hypothesis is confirmed by other studies, general physicians should pay attention to the appearing of $\mathrm{AKN}$ in overweight or obese patients in order to avoid its progression to disfiguring permanent scarring alopecia. On the other hand, dermatologists must pay attention to overweight, obesity, and other metabolic disorders, reminding AKN patients should be assessed beyond the skin.

\section{Statement of Ethics}

The study complies with the internationally accepted standards for research practice and reporting. Subjects have given their written informed consent to publish photos and details of the case.

\section{Conflict of Interest Statement}

The authors have no conflicts of interest to declare.

\section{Funding Sources}

This research did not receive any specific grant from funding agencies in the public, commercial, or not-for-profit sectors.

\section{Author Contributions}

A.M.M. and D.F.M. conceived the study and wrote the manuscript; V.D.T. and L.R.P. collected data; and C.J.M. analyzed and interpreted data. All authors discussed the results and reviewed the final manuscript.

\section{References}

1 Doche I, Coelho EQ, Quaresma MV, Matta Rivitti-Machado MC. Acne keloidalis nuchae and folliculitis decalvans: same process affecting the follicle or coexisting diseases? A retrospective study. Int J Dermatol. 2019;58(10): e200-3.

2 Chouk C, Litaiem N, Jones M, Zeglaoui F. Acne keloidalis nuchae: clinical and dermoscopic features. BMJ Case Rep. 2017:bcr2017.

$3 \mathrm{Na} \mathrm{K}, \mathrm{Oh} \mathrm{SH}, \mathrm{Kim}$ SK. Acne keloidalis nuchae in Asian: a single institutional experience. PLoS One. 2017;12(12):e0189790.

4 Knable Jr AL, Hanke CW, Gonin R. Prevalence of acne keloidalis nuchae in football players. J Am Acad Dermatol. 1997;37(4): $570-4$.

5 Ogunbiyi A, Adedokun B. Perceived aetiological factors of folliculitis keloidalis nuchae (acne keloidalis) and treatment options among Nigerian men. Br J Dermatol 2015; 173(Suppl 2):22-5.

6 East-Innis ADC, Stylianou K, Paolino A, Ho JD. Acne keloidalis nuchae: risk factors and associated disorders: a retrospective study. Int J Dermatol. 2017;56(8):828-32.
7 Khumalo NP, Jessop S, Gumedze F, Ehrlich R. Hairdressing and the prevalence of scalp disease in African adults. Br J Dermatol. 2007; 157(5):981-8

8 George AO, Akanji AO, Nduka EU, Olasode JB, Odusan O. Clinical, biochemical and morphologic features of acne keloidalis in a black population. Int J Dermatol. 1993;32(10): 714-6.

9 Loayza E, Cazar T, Uraga V, Lubkov A, Garces JC. Acne keloidalis nuchae in Latin American women. Int J Dermatol. 2015;54(5): e183-5.

10 Verma SB, Wollina U. Acne keloidalis nuchae: another cutaneous symptom of metabolic syndrome, truncal obesity, and impending/overt diabetes mellitus? Am J Clin Dermatol. 2010;11(6):433-6.

11 Loayza E, Vanegas E, Cherrez A, Ojeda IC. Acne keloidalis nuchae in Latin America: is there a different phenotype? Int J Dermatol. 2017;56(12):1469-70.

12 Sperling L, Homoky C, Pratt L, Sau P. Acne keloidalis is a form of primary scarring alopecia. Arch Dermatol. 2000;136(4):479-84.

13 Janjua SA, Iftikhar N, Pastar Z, Hosler GA. Keratosis follicularis spinulosa decalvans associated with acne keloidalis nuchae and tufted hair folliculitis. Am J Clin Dermatol. 2008; 9(2):137-40.
14 Azurdia RM, Graham RM, Weismann K, Guerin DM, Parslew R. Acne keloidalis in Caucasian patients on cyclosporin following organ transplantation. Br J Dermatol. 2000; 143(2):465-7.

15 Pirmez R, Price VH, Cuzzi T, Moritz BT. Acne keloidalis nuchae in renal transplant patients receiving tacrolimus and sirolimus. Australas J Dermatol. 2016;57(2):156-7.

16 Grunwald MH, Ben-Dor D, Livni E, Halevy S. Acne keloidalis-like lesions on the scalp associated with antiepileptic drugs. Int J Dermatol. 1990;29(8):559-61.

17 Saka B, Akakpo AS, Téclessou JN, MouhariToure A, Kassang P, Gnossike P, et al. Risk factors associated with acne keloidalis nuchae, in black subjects: a case-control study. Ann Dermatol Venereol 2020;147(5):350-4.

18 Yosipovitch G, DeVore A, Dawn A. Obesity and the skin : skin physiology and skin manifestations of obesity. Jounal Am Acad Dermatology. 2007;56(6):901-16.

19 Coimbra S, Catarino C, Santos-Silva A. The triad psoriasis-obesity-adipokine profile. J Eur Acad Dermatology Venereol. 2016; 30(11):1876-85.

20 Miller IM, McAndrew RJ, Hamzavi I. Prevalence, risk factors, and comorbidities of hidradenitis suppurativa. Dermatol Clin. 2016; 34(1):7-16. 